\title{
ANATOMICAL VARIATIONS OF NODAL ARTERIES IN HUMAN HEARTS.
}

Anjali S Sabnis, Nazmeen N Silotry

1. Associate Professor, Department of Anatomy, K. J. Somaiya Medical College, Sion, Mumbai,

2. Associate Professor, Department of Anatomy, MGM Medical College,Kamothe,Navi Mumbai.

\section{CORRESPONDING AUTHOR}

Dr. Anjali S. Sabnis,

D/3, Madhuban Society,

Atur Park, Chembur, Mumbai-71

E-mail: dranjus2003@yahoo.com,

Ph: 00919820493036.

ABSTRACT: BACKGROUND: Initiation of each heart beat is at sino-atrial (S.A) node and then it is transmitted to atrio-ventricular (A.V) node. The nodal arteries usually arise from Right Coronary Artery (RCA). The present study would be of use to cardiologists and interventional radiologist during invasive \& non-invasive procedures. AIMS: The aim of the study is to investigate the anatomical variance in nodal arteries in human hearts. MATERIAL \& METHODS: Study included 110 human hearts of both sexes between the ages of 20 to70 years obtained from Maharashtra were dissected to study coronary arteries. The S.A nodal and A.V nodal arteries were studied in detail in terms of their origin, course, diameter \& length. RESULTS: In the study we found that S.A.node was supplied by RCA in 99 hearts and from left coronary artery (LCA) in 11 hearts while A.V node was supplied RCA in 77 hearts and by LCA in 32 hearts. In one heart it was supplied by both the coronary arteries. CONCLUSION: The data extracted from this study will be helpful for cardiac surgeons during atrial surgical interventions, radiologists and anatomists.

KEY WORDS: nodal arteries, S.A nodal artery, A.V nodal artery.

INTRODUCTION: S.A node is spindle shaped structure present at the junction of superior vena cava and right atrium. It acts as a pacemaker which fires at regular interval. The impulses reach AV node which is beneath the right atrial endocardium anterior to ostium of coronary sinus and directly above the insertion of septal leaflet of tricuspid valve. The main function of AV node is modulation of atrial impulse transmission to the ventricles, there by coordinating atrial and ventricular contractions ${ }^{1}$.

SA node and AV node are the important structures in the conductive system of the heart. The arterial supply to S.A node and A.V node is also considered to be very important. The origin of S.A nodal artery is variable, when it comes from RCA it usually comes from anterior stem, When comes from LCA it arises from circumflex branch ${ }^{2}$. During the surgical procedures used in the treatment of arrhythmia injury to nodal arteries remains important possibility. So during the dissection of coronary arteries nodal arteries were studied in detail in terms of origin, course, diameter \& length. Such detailed information regarding nodal arteries will be helpful in the application of cardiac surgery.

MATERIALS AND METHODS: 110 human hearts of both sexes between the age of 20 to 70 years were collected from B.J. Medical college and K.J.Somaiya medical college in the period for two years. They were numbered serially \& fixed in $10 \%$ formalin solution. All hearts were dissected after the removal of epicardium. The right coronary artery, left coronary artery and 
their branches to SA and AV node were dissected from origin to termination. The point of origin, course, external diameter \& length of nodal arteries was studied. The length of nodal arteries was measured with the help of measuring scale and external diameter of S.A nodal artery at the origin was measured with divider and measuring scale.

\section{RESULTS}

\section{Table No 1. Shows origin of S. A \& A.V nodal artery}

\begin{tabular}{|l|l|l|}
\hline Origin From & S.A nodal artery & A.V nodal artery \\
\hline Right Coronary Artery & 99 hearts $((90 \%)$ & 77 hearts $(70 \%)$ \\
\hline \multicolumn{1}{|c|}{ Left Coronary Artery } & 11 hearts $(10 \%)$ & 32 hearts $(29.8 \%)$ \\
\hline Both Coronary arteries & - & 01 heart $(0.96 \%)$ \\
\hline Total no of hearts & 110 & 110 \\
\hline
\end{tabular}

- Among110, in 99 hearts S.A nodal artery was originated from RCA except in one heart where the artery originated from right marginal artery, rests originated from circumflex branch of LCA.

- In 77 hearts S.A nodal artery was originated from RCA, in 32 hearts it is originated from circumflex branch of LCA \& in one heart it was originated from both coronary arteries.

- Table No 2 shows mean diameter and mean length of nodal arteries

\begin{tabular}{|l|l|l|l|l|l|}
\hline \multicolumn{3}{|c|}{ S A Nodal artery } & \multicolumn{3}{c|}{ A V Nodal artery } \\
\hline $\begin{array}{l}\text { Mean } \\
\text { Diameter }\end{array}$ & \multicolumn{2}{|l|}{ Mean Length } & Mean Diameter & Mean Length \\
\hline $1.1 \mathrm{~mm}$ & From RCA & From LCA & $1.2 \mathrm{~mm}$ & From RCA & From LCA \\
\cline { 2 - 5 } & $35 \mathrm{~mm}$ & $70 \mathrm{~mm}$ & & $2 \mathrm{~mm}$ & $4 \mathrm{~mm}$ \\
\hline
\end{tabular}

DISCUSSION: S.A node was first described by Keith \& Flack in 19073. It is a pacemaker and considered very important structure in the heart. The blood supply of this important structure has great value due to its functional importance. It usually comes from first part of right coronary artery, runs back in the sulcus between right auricle and aorta and branched around superior vena caval base. A ramus traverses S.A node and supplies it ${ }^{4}$. Vascular descriptions of nodal arteries have been reported in several published articles in literature and we agree that in majority of hearts nodal arteries are given by right coronary artery.

Table no 3 shows results of various authors $5,6,7,8,9$.

\begin{tabular}{|l|l|l|l|l|l|l|l|}
\hline & Name of author & $\begin{array}{l}\text { SA nodal } \\
\text { from } \\
\text { RCA }\end{array}$ & $\begin{array}{l}\text { SA nodal } \\
\text { from LCA }\end{array}$ & $\begin{array}{l}\text { SA nodal } \\
\text { from RCA } \\
\text { \& LCA }\end{array}$ & $\begin{array}{l}\text { AV nodal } \\
\text { from RCA }\end{array}$ & $\begin{array}{l}\text { AV nodal } \\
\text { from LCA }\end{array}$ & $\begin{array}{l}\text { AV nodal } \\
\text { from RCA \& } \\
\text { LCA }\end{array}$ \\
\hline 1 & Shilpa Bhimani & & & \\
\hline 2 & Pejkovic $\mathrm{B}^{6}$ & $66.6 \%$ & $25 \%$ & $3.3 \%$ & $80 \%$ & $16 \%$ & Absent in $3.3 \%$ \\
\hline 3 & Hutchinson $\mathrm{MC}^{7}$ & $50 \%$ & $37 \%$ & -- & $90 \%$ & $10 \%$ & -- \\
\hline 4 & Lakshmi Raman $^{8}$ & $53 \%$ & $42 \%$ & $4.33 \%$ & $72.4 \%$ & $27.6 \%$ & -- \\
\hline 5 & Futamic & $07 \%$ & & & & \\
\hline $\mathbf{6}$ & Present study & $73 \%$ & $3 \%$ & $23 \%$ & $80 \%$ & $10 \%$ & $10 \%$ \\
\hline
\end{tabular}


There is high risk for intra-operative damage to S.A node during the superior transseptal approach to mitral valve ${ }^{10}$. The point of origin, length, diameter \& course of nodal arteries provides important information prior to surgical cardiac procedures. So by keeping this importance in mind, the point of origin of S.A.nodal artery was studied by measuring distance between origin of right coronary artery and origin of S.A nodal artery. In all hearts it is taking origin at mean distance of $35 \mathrm{~mm}$ from origin of right coronary artery (photograph no 1) with average length of $35 \mathrm{~mm}$ \& diameter of $1.1 \mathrm{~mm}$. The mean length of S.A nodal artery is $23 \mathrm{~mm}^{5}$, $12 \mathrm{~mm}^{6}, 40.1$ to $134 \mathrm{~mm}^{11}$ \& diameter is $1 \mathrm{~mm}^{5}, 1.7 \mathrm{~mm}^{6}, 1.1 \mathrm{~mm}^{11}$ within the node. In one of the 40 autopsy cases S.A nodal artery arose from the terminal part of right coronary artery ${ }^{7}$.We did not notice any such origin from terminal part of right coronary artery.

In one heart right marginal artery was arising from right coronary artery much proximally. S.A nodal artery took origin from right marginal artery instead of right coronary artery (photograph no 3). It traveled around lateral border of right auricle and encircled the whole auricle and reached the base of superior vena cava ramifying there and supplying S.A node. Such origin from right marginal artery is not yet documented.

In 11 hearts (10\%) S.A nodal artery was arising from circumflex artery with mean length of $70 \mathrm{~mm} \&$ diameter of $1 \mathrm{~mm}$ (photograph no 2). In all hearts it traveled from posterior aspect of heart and reaches S.A node. None of the heart showed S.A nodal artery coming from trunk of left coronary artery.In $12 \%$ of cases it is arising from trunk ${ }^{12} \&$ mean diameter is 2.2 $\mathrm{mm}^{6}$.

A.V node was first described by Tarawa in $1906^{3}$. It is a specialized tissue present in the posteroinferior region of the interatrial septum near the opening of coronary sinus. It electrically connects atrial and ventricular chambers ${ }^{13}$. The main function of A.V node is modulation of atrial impulse transmission to the ventricles, there by coordinating atrial and ventricular contractions. It delays the impulse received from S.A node and protect ventricles from atrial arrhythmia. The largest posterior septal artery from right coronary artery which is given at crux enters the interatrial septum and supplies A.V node. This artery is important vessel in the pathogenesis of heart block. Any variation in point of origin, course may provide information prior to catheter based interventional cardiac procedure ${ }^{14}$.

With respect to that we have studied point of origin, course, length \& diameter of A.V nodal artery. We found that A.V nodal artery is arising from RCA in 70\% hearts with mean length of $2 \mathrm{~mm}$, from circumflex artery in 29\% hearts with mean length of $4 \mathrm{~mm}$ and from both the arteries in $0.9 \%$ heart. The mean external diameter is $1.2 \mathrm{~mm}$. The origin of A.V nodal artery from right coronary artery is $90 \% 5,80 \%^{8}$, from left coronary artery is $10 \% 5$, \& from both arteries is $10 \%{ }^{8}$ with mean diameter of $2 \mathrm{~mm}^{5}$.

Awareness of anatomical variants of S.A nodal \& A.V nodal arteries may guide the cardiac surgeons during cardiac procedures and reduces the risk of damaging them. The damage in the form of cut or occlusion will not give chance for repair \& so special care should be taken to spare the artery during surgery.

Conclusion:

Detail knowledge of nodal arteries \& awareness of variations is important from surgical point of view. 


\section{ORIGINAL ARTICLE}

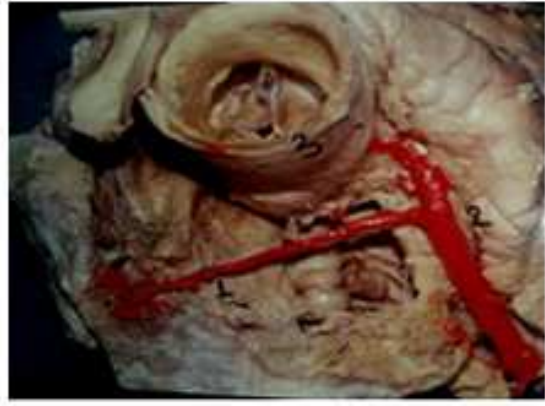

Photograph No 1 shows S.A nodal artery (1) is arising from 1st part of Right coronary artery (2)

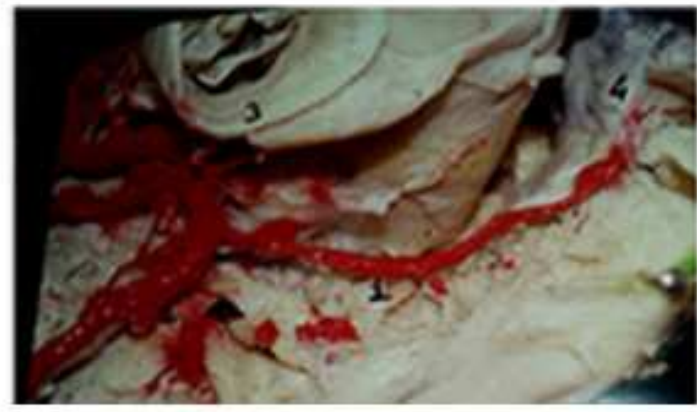

Photograph No 2 shows S.A nodal artery (1) is arising from circumflex artery (2)

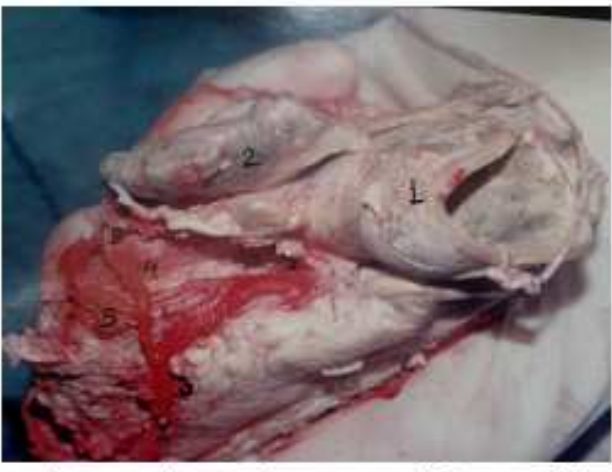

Photograph No 3 shows S.A. nodal artery (4) is arising from right marginal artery (3)

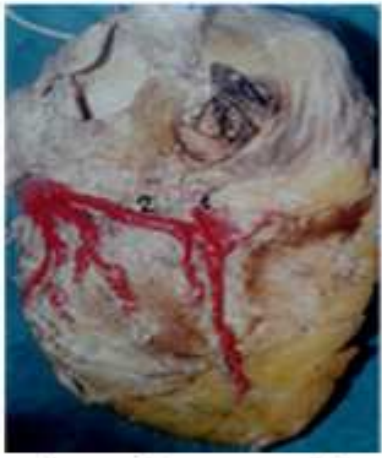

Photograph No 5 shows A.V nodal artery (1) is arising from circumflex artery (2)

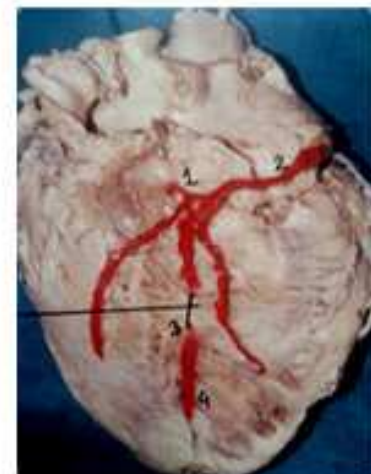

Photograph No 4 shows A.V nodal artery (1) is arising from right coronary artery(2)

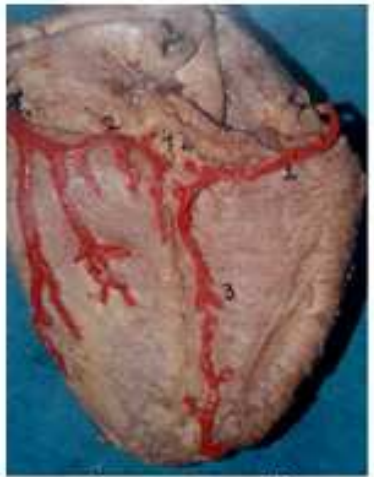

Photograph No 6 shows A.V nodal artery (4) is arising from right coronary artery (1) \& left coronary artery (2)

\section{REFERENCES:}

1. Lilly LS, Libby P, Bonow R, Mann D, Zips D. Braunwald's Heart Disease, 8th edition, Saunders, Philadelphia, 2008, p-727-762.

2. Susan Standring, Gray's Anatomy, 40thedition, Churchill Livingstone, Elsevier, London, 2008, pp-978-980

3. Hurst, Willis J. The Heart. $7^{\text {th }}$ edition, Vol I, Part I, Mc-Graw Hill, New york, Information sevices company 1990, p-14-35. 
4. Lawrence H. Bannister, Gray's Anatomy, 38 th edition, Churchill Livingstone, London, 1995, pp-1451-1500,

5. Bhimalli S. A study of variations in coronary arterial system in cadaveric human heart. World J of science and technology, 2011,1(5):30-35

6. Pejkovic B. Anatomical aspects of the arterial blood supply to the sinoatrial and atrioventricular nodes of the human heart. J Int Med Res,2008;36(4):691-8

7. Hutchinson M C, A study of the artrial arteries in man J Anat:1978;125(1);39-54

8. Lakshmi R. Origin of the Sinoatrial and atrioventricular Nodal arteries in South Indians: an Angiographic Study, Arq Brs Cardiol, 2009:92(5)-319.

9. Futami C,The arterial blood supply of the conducting system in normal human hearts,Surg Radiol Anat,2003,25(1):42-9.

10. Berdajs D, The clinical anatomy of the sinus node artery.Ann Thorac Surg, 2003; 76:732-5.

11. Ortale JR. Anatomical Variations in human S.A nodal artery, Clinics 2006; 61(6)5518.

12. Caetano A G. Critical analysis of the clinical and surgical importance of the variations in the origin of the sinoatrial node artery of the human heart.Rev Assoc Med Bras.1995:41(2):94-102.

13. Gray, Huon H, Keith D, Dawkins L, Simpson A \& John M Morgan, Lecture notes on cardiology Boston ; Blackwell Science,2002, P-135,ISBN 978-0-86542-864-5

14. Duzgun Y, Anatomy \& variations of arterial supply to sinoatrial node: Imaging with dual source cardiac multidetector CT angiography, Turk Gogus Kalp Damar Cer Derg 2010;18(4)290-292 